\title{
Medical Treatment for Ectopic Pregnancy during the COVID-19 Pandemic
}

\author{
Júlio Elito Júnior ${ }^{1(1)}$ Edward Araujo Júnior ${ }^{1}$ (1) \\ 1 Department of Obstetrics, Escola Paulista de Medicina, Universidade \\ Federal de São Paulo, São Paulo, SP, Brazil \\ Rev Bras Ginecol Obstet 2020;42(12):849-850.
}

Address for correspondence Edward Araujo Júnior, PhD, Departamento de Obstetrícia, Escola Paulista de Medicina, Universidade Federal de São Paulo, R. Botucatu, 740, Vila Clementino, São Paulo, SP, 04023-062, Brazil (e-mail: araujojred@terra.com.br).

Once the patient was selected, the next step was to define the MTX regimen: single dose of MTX $50 \mathrm{mg} / \mathrm{m}^{2}$, two doses (50 mg/m ${ }^{2}$ on days 1 and 4), multiple doses (MTX $1 \mathrm{mg} / \mathrm{kg}$ on days $1,3,5$, and 7 and folinic acid $0.1 \mathrm{mg} / \mathrm{mg}$ on days $2,4,6$, and 8 ). The single dose is the most commonly used regimen in patients with tubal pregnancy. Follow-up could be performed by telemedicine, with a focus on the $\beta$-hCG levels on days 4 and 7 after MTX regimen. If the levels decrease by more than $15 \%$ between days 4 and 7 , the response is considered favorable. The patient should be followed up with $\beta$-hCG titers every week until the levels become negative. On the other hand, if the $\beta$-hCG level decrease by less than $15 \%$ between days 4 and 7 , this indicates that an increase in MTX dose is necessary. ${ }^{3}$

Expectant management can be performed in patients with declining $\beta$-hCG levels at an interval of 24/48 hours before treatment. The main criteria for expectant management are unruptured ectopic pregnancy, hemodynamically stable, declining levels of $\beta$-hCG at an interval of $24 / 48$ hours, $\beta$-hCG levels $\leq 2,000 \mathrm{mUI} / \mathrm{ml}$, tubal pregnancy diameter $\leq 3.5 \mathrm{~cm}$, and absence of embryonic cardiac activity detected by transvaginal ultrasonography. ${ }^{4}$ The surveillance is performed to check $\beta$ hCG levels every week until the titers become negative.

Surgery for tubal pregnancy should be performed in patients with ruptured tubal pregnancy, high levels of $\beta$ hCG, adnexal mass $>3.5 \mathrm{~cm}$, and presence of live embryo. Patients diagnosed with COVID-19 should undergo laparoscopy because the MTX regimen could reduce immunity, and active pulmonary disease is a contraindication for MTX.

In most cases of non-tubal ectopic pregnancy (cervical, cesarean scar, interstitial and ovarian pregnancy), the standard treatment is surgery, such as hysterectomy. Some procedures alternative to surgery include local injection of MTX guided by transvaginal ultrasound, systemic medical treatment with MTX, and embolization of uterine arteries. Management in cases of interstitial, cervical, and cesarean scar pregnancies should always be on a case by case basis. When the embryo has

Copyright (c) 2020 by Thieme Revinter Publicações Ltda, Rio de Janeiro, Brazil
License terms

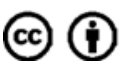

received

June 12,2020

accepted

August 3, 2020
DOI https://doi.org/

10.1055/s-0040-1718438. ISSN 0100-7203. 
a heartbeat, transvaginal ultrasonography-guided local treatment with MTX injection into the gestational sac at a dose of $1 \mathrm{mg} / \mathrm{kg}$ is the first-line treatment. Systemic treatment with MTX is performed in cases in which the embryo has no heartbeat. Medical treatment will depend on the initial $\beta$ hCG titer. For titers $<5,000 \mathrm{mIU} / \mathrm{mL}$, a single dose of MTX $50 \mathrm{mg} / \mathrm{m}^{2}$ is recommended. On the other hand, if $\beta$-hCG titers are $>5,000 \mathrm{mIU} / \mathrm{ml}$, a multiple-dose MTX protocol is recommended.

In summary, clinical treatment of ectopic pregnancy by MTX or expectant management is an alternative during the COVID19 pandemic. An early diagnosis and appropriate selection of treatment options are critical for the success of the treatment.

Conflict of Interests

The authors have no conflict of interests to declare.

\section{References}

1 Cecchino GN, Araujo Júnior E, Elito Júnior J. Methotrexate for ectopic pregnancy: when and how. Arch Gynecol Obstet. 2014; 290(03):417-423. Doi: 10.1007/s00404-014-3266-9

2 Chu DK, Akl EA, Duda S, Solo K, Yaacoub S, Schünemann HJCOVID19 Systematic Urgent Review Group Effort (SURGE) study authors. Physical distancing, face masks, and eye protection to prevent person-to-person transmission of SARS-CoV-2 and COVID-19: a systematic review and meta-analysis. Lancet. 2020;395 (10242):1973-1987. Doi: 10.1016/S0140-6736(20)31142-9

3 Committee on Practice Bulletins-Gynecology. ACOG Practice Bulletin No. 191: tubal ectopic pregnancy. Obstet Gynecol. 2018;131(02):e65-e77. Doi: 10.1097/AOG.0000000000002464

4 Silva PM, Araujo Júnior E, Cecchino GN, Elito Júnior J, Camano L. Effectiveness of expectant management versus methotrexate in tubal ectopic pregnancy: a double-blind randomized trial. Arch Gynecol Obstet. 2015;291(04):939-943. Doi: 10.1007/s00404014-3513-0 